\title{
Whole grain intake and its cross-sectional association with obesity, insulin resistance, inflammation, diabetes and subclinical CVD: The MESA Study
}

\author{
Pamela L. Lutsey ${ }^{1}$, David R. Jacobs $\mathrm{Jr}^{1,2} *$, Sujata Kori ${ }^{3}$, Elizabeth Mayer-Davis ${ }^{4}$, Steven Shea $^{5}$, \\ Lyn M. Steffen ${ }^{1}$, Moyses Szklo ${ }^{6}$ and Russell Tracy ${ }^{7}$ \\ ${ }^{1}$ University of Minnesota School of Public Health, Division of Epidemiology and Community Health; Minneapolis, MN, USA \\ ${ }^{2}$ The Institute of Nutrition Research, University of Oslo; Oslo, Norway \\ ${ }^{3}$ Cardiology Consultants of Orange County; Anaheim, CA, USA \\ ${ }^{4}$ University of South Carolina Center for Research in Nutrition and Health Disparities Arnold School of Public Health; \\ Columbia, SC, USA \\ ${ }^{5}$ Columbia University Mailman School of Public Health and College of Physicians and Surgeons; New York, NY, USA \\ ${ }^{6}$ Johns Hopkins University Department of Epidemiology; Baltimore, MD, USA \\ ${ }^{7}$ University of Vermont Department of Pathology - Colchester Research Facility; Colchester, VT, USA
}

(Received 24 August 2006 - Revised 15 December 2006 - Accepted 31 January 2007)

\begin{abstract}
We examined the relationship between whole grain intake and obesity, insulin resistance, inflammation, diabetes and subclinical CVD using baseline data from the Multi-Ethnic Study of Atherosclerosis. Whole grain intake was measured by a 127 -item FFQ in 5496 men and women free of CHD and previously known diabetes. Mean whole grain intake was 0.5 (SD 0.5) servings per d; biochemical measures reflect fasting levels. After adjustment for demographic and health behaviour variables, mean differences for the highest quintile of whole grain intake minus the lowest quintile of intake were $0.6 \mathrm{~kg} / \mathrm{m}^{2}$ for BMI, $0.36 \mathrm{mg} / \mathrm{l}$ for C-reactive protein, $0.82 \mu \mathrm{mol} / 1$ for homocysteine, $0.15 \mathrm{mU} / \mathrm{l}^{*} \mathrm{mmol} / 1 \mathrm{for}$ homeostasis model assessment (HOMA), $0.48 \mathrm{mU} / \mathrm{l}$ for serum insulin, $2.0 \mathrm{mg} / \mathrm{dl}$ for glucose and $5.7 \%$ for prevalence of newly diagnosed impaired fasting glucose (glucose $\geq 100 \mathrm{mg} / \mathrm{dl}$ or diabetes medication). These differences represent $11-13 \%$ of a standard deviation of BMI, HOMA, glucose and impaired fasting glucose, but $23 \%, 52 \%$ and $80 \%$ of a standard deviation of homocysteine, C-reactive protein and insulin, respectively. An inverse association between whole grains and urine albumin excretion was suggested but retained statistical significance after adjustment only in Chinese and Hispanic participants. No associations were observed between whole grain intake and two subclinical disease measures: carotid intima-media thickness and coronary artery calcification. Concordant with previous research, whole grain intake was inversely associated with obesity, insulin resistance, inflammation and elevated fasting glucose or newly diagnosed diabetes. Counter to hypothesis, however, whole grain intake was unrelated to subclinical CVD.
\end{abstract}

Whole grains: CVD disease risk: Microalbuminuria: subclinical CVD

Whole grain intake has been related to reductions in total mortality (Jacobs et al. 1999, 2001), coronary artery disease mortality and morbidity (Morris et al. 1977; Fraser et al. 1992; Pietinen et al. 1996; Jacobs et al. 1998; Liu et al. 1999; Steffen et al. 2003b) and diabetes incidence (Liu et al. 2000; Meyer et al. 2000; Fung et al. 2002; Montonen et al. 2003), independent of other health behaviours. In a review of whole grain intake, Jacobs \& Gallaher (2004) found that habitual consumers of whole grain consistently had a $20-40 \%$ reduction in long-term risk of coronary artery disease and type II diabetes as compared with those who rarely ate whole grains. This evidence contributed to an emphasis on the consumption of whole grains in the 2005 US Department of Agriculture Dietary Guidelines for Americans, which state: 'Consume 3 or more ounce-equivalents of whole-grain products per day, with the rest of the recommended grains coming from enriched or whole-grain products. In general, at least half the grains should come from whole grains' (http://www.healthierus.gov/dietaryguidelines) (US Department of Health \& Human Services \& the US Department of Agriculture (2005).

Whole grain food intake and dietary fibre intake, especially from cereal sources, have also been associated with favourable levels of insulin sensitivity (Lovejoy \& DiGirolamo, 1992; Feskens et al. 1994; Vitelli et al. 1996; Marshall et al. 1997; Pereira et al. 2002; Liese et al. 2003; Steffen et al. 2003a;), BMI (Pereira et al. 2002; Steffen et al. 2003a) and 10-year weight gain (Ludwig et al. 1999). Despite the strong body of evidence relating high consumption of whole grain food intake to CVD risk factors and CVD morbidity and

Abbreviations: A/kC, urine albumin:creatine ratio; CAC, coronary artery calcification; CRP, C-reactive protein; MESA, Multi-Ethnic Study of Atheroscelerosis. * Corresponding author: David R. Jacobs Jr., fax +1 612624 0315, email Jacobs@epi.umn.edu 
mortality, there have been no studies of whole grain food and subclinical atherosclerosis. Additionally, little research has assessed whether racial/ethnic heterogeneity exists in the relationship between whole grain intake and various CVD risk factors.

This paper focuses on the cross-sectional relationship between whole grain intake and selected CVD risk factors and measures of subclinical atherosclerosis using baseline data from the Multi-Ethnic Study of Atherosclerosis (MESA). We hypothesized that whole grain intake would be inversely associated with the following variables: BMI; serum insulin; C-reactive protein (CRP); IL-6; homocysteine; newly diagnosed diabetes and impaired fasting glucose; urine albumin:creatinine ratio $(\mathrm{A} / \mathrm{kC})$; carotid artery intima-media thickness; presence of coronary artery calcification (CAC).

\section{Methods}

\section{Subjects}

MESA is a prospective epidemiological cohort study initiated in July 2000 with the aim of exploring the prevalence, correlates and progression of subclinical and clinical CVD, with focus on assessing possible differences between non-Hispanic whites, Hispanics, African Americans and Chinese. A full description of the design and methods has been published elsewhere (Bild et al. 2002). The MESA protocol was approved by local institutional review committees and all subjects gave informed consent. A total of 6814 men and women between the ages of 45 and 84 years, all of whom were free of clinical CVD at baseline, were selected from six US field centres.

Participants who had no diet data ( $n$ 577) or implausible energy intakes as defined by consuming $>25081 \mathrm{~kJ} / \mathrm{d}$ $(6000 \mathrm{kcal} / \mathrm{d})$ or $<2508 \mathrm{~kJ} / \mathrm{d} \quad(600 \mathrm{kcal} / \mathrm{d}) \quad(n$ 157) were excluded. Furthermore, participants were excluded if they had been previously diagnosed with diabetes ( $n$ 610), as these individuals may have changed their diets in response to disease. These criteria were not mutually exclusive, thus the present report includes baseline data on 5496 participants.

\section{Data collection}

Dietary assessment. At baseline, diet was assessed using a staff-assisted self-administered 127-item FFQ and dietary supplement form in Block format (Block et al. 1990). For each questionnaire item, participants were asked to report their frequency of consumption of various foods from among nine categories, ranging from rarely or never to two or more servings/ $\mathrm{d}$ (six or more servings/d for beverages) and also their serving size as either small, medium or large. Servings per d were calculated from these categories. The FFQ was patterned after the FFQ used in the Insulin Resistance Atherosclerosis Study, which has been validated in non-Hispanic white, AfricanAmerican and Hispanic persons (Mayer-Davis et al. 1999). Concerning validity, the mean correlation coefficients between nutrient intake estimated from the FFQ and intake from the average of eight 24-h recalls were 0.62 for non-Hispanic whites, 0.50 for African Americans and 0.41 for Hispanics. For total carbohydrates the correlation coefficient was $0 \cdot 39$. Among non-Hispanic whites, however, carbohydrate intake estimated from the FFQ tended to be lower than carbohydrate intake estimated from the dietary recalls. Concerning reproducibility, the mean correlation coefficient for nutrients across two administrations of the FFQ was 0.62 and did not differ by ethnic subgroup. In order to accommodate the MESA subject population, the Insulin Resistance Atherosclerosis Study FFQ was modified to include Chinese foods and culinary practices.

\section{Whole grain intake}

Servings per $d$ of the following foods were summed to calculate total whole grain intake: whole grain breakfast cereal; oatmeal; dark bread; bran muffins; brown or wild rice. Further descriptions of whole grain food items, including verbatim FFQ wordings, are provided in Table 1.

If participants reported eating cold cereal, they were asked to name the breakfast cereal that they usually ate. Breakfast cereals mentioned were then evaluated for dietary fibre and whole grain content as determined by package labels, dietary

Table 1. Descriptions of mean intake of whole grain food groups among Multi-Ethnic Study of Atherosclerosis participants†

\begin{tabular}{|c|c|c|c|c|c|c|c|}
\hline \multirow[b]{2}{*}{ Whole grain item } & \multicolumn{2}{|c|}{$\begin{array}{c}\text { No. of } \\
\text { servings/d }\end{array}$} & \multicolumn{2}{|c|}{$\begin{array}{l}\text { No. and proportion } \\
\text { consuming }\end{array}$} & \multicolumn{2}{|c|}{$\begin{array}{l}\text { No. of servings/d } \\
\text { among consumers }\end{array}$} & \multirow{2}{*}{$\begin{array}{l}\text { Verbatim wording for } \\
\text { food items included }\end{array}$} \\
\hline & Mean & SD & $n$ & $\%$ & Mean & SD & \\
\hline Total whole grains & 0.54 & 0.54 & 4973 & $90 \cdot 5$ & 0.59 & 0.53 & \\
\hline $\begin{array}{l}\geq 1 \text { serving } / d \\
\geq 3 \text { serving } / d\end{array}$ & & & $\begin{array}{r}1074 \\
18\end{array}$ & 19.5 & & & \\
\hline $\begin{array}{l}\text { Cold cereal } \\
\text { (whole grain) }\end{array}$ & 0.15 & 0.29 & 2082 & $\begin{array}{l}0.33 \\
37.9\end{array}$ & 0.40 & 0.36 & $\begin{array}{l}\text { Cold breakfast cereal; If you eat cold } \\
\text { cereal, what is the name of the cold } \\
\text { cereal that you most often eat? }\end{array}$ \\
\hline Oatmeal & 0.17 & 0.28 & 3331 & $60 \cdot 6$ & $0 \cdot 28$ & 0.31 & Oatmeal \\
\hline Dark bread & $0 \cdot 13$ & $0 \cdot 25$ & 2761 & $50 \cdot 2$ & $0 \cdot 25$ & $0 \cdot 30$ & $\begin{array}{l}\text { Dark, whole grain breads or rolls } \\
\text { (hamburger buns, bagels, pita, } \\
\text { English muffins, etc.) }\end{array}$ \\
\hline Bran muffins & 0.03 & $0 \cdot 10$ & 1390 & $25 \cdot 3$ & $0 \cdot 10$ & $0 \cdot 19$ & Bran muffins \\
\hline Brown or wild rice & 0.06 & 0.17 & 2301 & 41.9 & 0.14 & 0.23 & Brown or wild rice \\
\hline
\end{tabular}

${ }^{*}$ Cold cereals were classified as either whole grain or refined grain. The classification criteria are described in Methods.

†For details of subjects and procedures, see Methods. 
databases, such as the Nutrition Data System and the US Department of Agriculture Food Composition Data, or by records shared in 1996 by General Mills, Inc (Minneapolis, $\mathrm{MN}$, USA). Of the 144 breakfast cereals mentioned, 121 were classified as whole grain cereals (most mentioned by very few participants) as they contained $\geq 3 \mathrm{~g}$ dietary fibre per $100 \mathrm{~g}$ dry weight. Given that $12 \mathrm{~g}$ dietary fibre corresponds to $100 \mathrm{~g}$ whole wheat, all wheat cereals classified as whole grain contained at least $25 \%$ of a serving of whole grain/ $100 \mathrm{~g}$. Of breakfast cereal consumers, $54.5 \%$ consumed whole grain varieties, while $45.6 \%$ consumed refined grain varieties. No nutrient available in the MESA database was closely correlated with whole grain food intake; the correlation with dietary fibre was $0.36(P<0.0001)$, while with total carbohydrates it was $0.29(P<0.0001)$.

BMI, serum insulin, newly diagnosed diabetes and impaired fasting glucose

BMI was calculated as weight over height squared $\left(\mathrm{kg} / \mathrm{m}^{2}\right)$. Participants were asked to fast for at least $8 \mathrm{~h}$. Serum insulin was measured by the Linco Human Insulin Specific RIA Kit (Linco Research, Inc., St. Charles, MO, USA), and serum glucose by rate reflectance spectrophotometry using thin film adaptation of the glucose oxidase method on the Vitros analyzer (Johnson \& Johnson Clinical Diagnostics, Inc., Rochester, NY, USA) at the Collaborative Studies Clinical Laboratory at Fairview University Medical Center (Minneapolis, MN, USA). Non-medicated participants with fasting glucose $\geq 7.0 \mathrm{mmol} / \mathrm{l}(126 \mathrm{mg} / \mathrm{dl})$ who did not self-report pre-existing diabetes were classified as newly diagnosed diabetics and those with fasting glucose levels between $5.6 \mathrm{mmol} / \mathrm{l}$ $(100 \mathrm{mg} / \mathrm{dl})$ and $6.9 \mathrm{mmol} / \mathrm{l}(125 \mathrm{mg} / \mathrm{dl})$ were classified as having impaired fasting glucose. The homeostasis model assessment (Matthews et al. 1985) estimate of insulin resistance was calculated as insulin*glucose/22.5 (mU/1*mmol/l).

\section{C-reactive protein, IL-6 and homocysteine}

CRP was measured using the BNII nephelometer (N High Sensitivity CRP; Dade Behring Inc., Deerfield, IL, USA) and IL-6 by an ultra-sensitive ELISA (Quantikine HS Human IL-6 Immunoassay; R\&D Systems, Minneapolis, MN, USA), both at the Laboratory for Clinical Biochemistry Research (University of Vermont, Burlington, VT, USA). Plasma total homocysteine was measured by a fluorescence polarization immunoassay (IMx Homocysteine Assay; Axis Biochemicals ASA, Oslo, Norway) using the IMx Analyzer (Abbott Diagnostics, Abbott Park, IL, USA) at the Biochemical Genetics Clinical Laboratory at Fairview University Medical Center (Minneapolis, MN, USA).

\section{Urine albumin excretion}

Urine albumin and creatinine concentrations were assayed in a single untimed urine sample at the Fletcher Allen Health Care Clinical Chemistry Laboratory (Burlington, VT, USA) Urine albumin was measured by the Array 360 CE Protein Analyzer (Beckman Instruments, Inc., Drea, CA, USA). Serum creatinine was measured by rate reflectance spectrophotometry using thin film adaptation of the creatine amidinohydrolase method on the Vitros analyzer (Johnson \& Johnson Clinical Diagnostics, Inc.). To estimate albumin excretion rate, sexstandardized $\mathrm{A} / \mathrm{kC}$ (where albumin is expressed as $\mu \mathrm{g} / \mathrm{ml}$ and creatinine is expressed as $\mathrm{mg} / \mathrm{ml}$ ) were calculated after multiplying men's urine creatinine concentrations by $\mathrm{k}$ $17 / 25$, based on the higher rate of creatinine excretion typical of men compared with women (Warram et al. 1996; Jacobs et al. 2002). The sex-standardized $\mathrm{A} / \mathrm{kC}$ is represented both linearly and dichotomously, with participants having values $\geq 25$ and $<250$ defined as having microalbuminuria (Jacobs et al. 2002). Participants with macroalbuminuria (A/kC $\geq 250 \mathrm{mg} / \mathrm{g}$ ) ( $n$ 127) were excluded in analyses of the urine albumin data.

\section{Carotid artery intima-media thickness}

Images of bilateral common carotid and internal carotid arteries were obtained via high-resolution B-mode ultrasonography using a Logiq 700 ultrasound machine (GE Medical Systems, Waukesha, WI, USA). Images of the near and far walls were obtained, on the basis of a previous study (O'Leary et al. 1999). Central reading of the intima-media thickness was done at Tufts-New England Medical Center (Boston, MA, USA) (Espeland et al. 2003); maximal intima-media thickness at any site was used in analysis. Additionally, a dichotomous variable indicated the presence of atherosclerotic plaque (any stenosis in either the right or left carotid artery).

\section{Coronary artery calcification}

Computed tomography of the coronary arteries was performed, as has been previously described (Carr et al. 2005), with electron beam scanners (Imatron C-150; Imatron, Inc., San Francisco, CA, USA) cardiac-gated at $80 \%$ of the R-R interval at three centres and with a prospective electrocardiogram-triggered scan acquisition at $50 \%$ of the R-R interval with multidetector scanners at the remaining three centres. The scanners are comparable in their ability to measure Ca (Carr et al. 2000). Scans were read centrally at Harbor University of California Medical Center (Los Angeles, CA, USA) and Agatston coronary artery $\mathrm{Ca}$ scores were quantified by blinded computer tomography (CT) image analysts. Participants with CAC scores $>0$ were considered to have $\mathrm{CAC}$ in the dichotomous variable representation.

\section{Additional variables}

Sex, race, age, educational level $(<$ high school, high school, some college, bachelor's degree, graduate or professional degree), current cigarette smoking (Yes/No), current alcohol use (Yes/No) and current hormone replacement therapy use (Yes/No) were self-reported. Physical activity was assessed using a detailed, semi-quantitative questionnaire adapted from the Cross-Cultural Activity Participation Study (B. Ainsworth, personal communication, San Diego State University). Leisure physical activity was computed as the sum of metabolic equivalent min/week of walking, conditioning, sports and dance, while a sedentariness score was the sum metabolic equivalent min/week of sitting or reclining, reading, knitting, sewing, etc, driving a car or watching television; metabolic equivalent activity 
intensity codes were based on a published table (Ainsworth et al. 2000). Neither separating former and never smokers nor treating alcohol as a continuous variable altered findings noticeably (data not shown).

HDL-cholesterol was measured in EDTA plasma using the cholesterol oxidase method (Roche Diagnostics, Indianapolis, IN, USA) after precipitation of non-HDL-cholesterol with Mg/ dextran, and LDL-cholesterol was calculated in plasma specimens having a TAG value $<400 \mathrm{mg} / \mathrm{dl}$ using the Friedewald formula, at the Collaborative Studies Clinical Laboratory at Fairview University Medical Center. Resting blood pressure was measured three times in the seated position using a Dinamap model Pro 100 automated oscillometric sphygmomanometer (Critikon, Tampa, FL, USA). The average of the last two measurements was used in analyses.

\section{Statistical analysis}

SAS was used for all analyses (version 9.1; SAS Institute, Inc., Cary, NC, USA). Mean levels of demographics, behaviours and physiological variables were provided by quintile of whole grain intake. Regression analyses were used to evaluate the association of each variable with whole grain intake, providing a $P$ value for trend over the continuous whole grain variable. Linear regression was used for continuous dependent variables (PROC GLM). Logistic regression (PROC GENMOD) was used for dichotomous dependent variables and provided the $P$ for trend. However, as logistic regression is a nonlinear procedure and therefore gives biased estimates of probabilities, which are on the arithmetic scale, linear regression was used to compute the adjusted percentages within whole grain intake quintiles for dichotomous dependent variables. The natural logarithm transformation was utilized because of skewness in serum insulin, $\mathrm{CRP}, \mathrm{A} / \mathrm{kC}$, the common carotid intimal-medial thickness, the internal carotid intimal-medial thickness and the Agatston score. Geometric means of these variables were reported. To account for Agatston scores of zero, one was added to all Agatston score values prior to transformation, then subtracted after exponentiation when estimating the geometric means.

Three models were developed to evaluate relationships with whole grain intake. Model 1 was adjusted for age, sex, race, education, survey centre and energy intake (base adjustment). Model 2, our primary model of interest, further adjusted for behavioural factors including current smoking (yes if one or more cigarettes/week or no), current alcohol use (Yes/No) and dietary intake of the following food groups: fruit; vegetables; refined grains; dairy; fish and poultry; meat. Model 3 (mechanistic model) was adjusted for model 2 factors as well as for BMI and serum insulin, two variables thought to be in the causal pathway between whole grain intake and CVD; these models were intended to assess whether observed relationships with whole grain intake were mediated by BMI or insulin. Furthermore, race/ethnicity interaction with whole grain food intake was assessed in each model for each dependent variable by adding the product of the continuous whole grain variable with the categorical race/ethnicity variable. Race/ethnicity interaction was insubstantial except for the dependent variable albumin excretion rate.

\section{Results}

The mean daily intake of whole-grain foods was 0.54 servings/ $\mathrm{d}$ (Table 1), while the median ranged from 0.02 servings/d for the lowest quintile of whole grain intake to 1.39 servings/d for the highest (Table 2). Whole grain intake varied by race, with whites having the highest mean intake $(0.60$ servings $/ \mathrm{d})$, followed by blacks ( 0.53 servings/d), Hispanics ( 0.52 servings/ d) and Chinese (0.32 servings/d).

After adjustment for age, sex, race, education, survey centre and energy intake, higher whole grain intake was strongly associated with race and being older, female, more educated, a non-smoker, more leisure physical activity, a lower sedentariness score and with consuming more energy, fruits, vegetables and dairy and less refined grains, meat and alcohol. Whole grain intake was not related to hormone replacement therapy, HDL-cholesterol, LDL-cholesterol, systolic blood pressure or diastolic blood pressure.

Inverse associations were found between whole grain intake and BMI, insulin, homeostasis model assessment insulin resistance, CRP and homocysteine (Table 3). In the case of CRP, $P$ for trend was not significant after possible mechanistic adjustment for BMI and insulin; however, the estimated mean CRP was lower in whole grain quintile 5 than $1(P=0 \cdot 009)$. IL-6 was inversely associated with whole grain consumption in model 1; however, this was attenuated with further adjustments. Whole grain intake was inversely related to glucose and to impaired fasting glucose or newly diagnosed diabetes (glucose $\geq 100 \mathrm{mg} / \mathrm{dl}$ ), but showed little relation to newly diagnosed diabetes when analysed separately.

Urine albumin excretion was inversely associated with whole grain intake after adjustment for age, sex, race, education, survey centre and energy intake. These relationships were attenuated with additional adjustments. The proportion of participants with microalbuminuria paralleled trends observed in urine albumin excretion levels. Associations of urine albumin excretion rate and whole grain intake (adjusted as in model 3) varied with race/ethnicity ( $P$ for interaction 0.03 ). The $\mathrm{A} / \mathrm{kC}$ was $12 \%$ and $19 \%$ lower per whole grain food serving per $\mathrm{d}$ among Hispanics $(P=0.03)$ and Chinese $(P=0 \cdot 02)$, respectively. These associations were null in whites and blacks.

Whole grain intake was inversely associated with probability of having any CAC in the base model, but this association was attenuated with further adjustment. Whole grain intake was not associated with carotid artery intima-media thickness or presence of plaque. These associations are presented in light of relatively low correlations among the different subclinical markers, which may suggest that each assesses a different aspect of subclinical CVD. The correlation between $\ln$ (Agatston score +1 ) and $\ln (\mathrm{A} / \mathrm{kC})$ was $r 0 \cdot 19$; $\ln ($ common carotid artery intima-media thickness) and $\ln (\mathrm{A} / \mathrm{kC})$ was $r$ $0 \cdot 19$; and between $\ln$ (common carotid artery intima-media thickness) and $\ln$ (Agatston score +1 ) was $r 0 \cdot 32$.

\section{Discussion}

In this multi-ethnic sample of 5496 men and women, mean whole grain consumption of about 0.5 servings per $d$ was slightly less than that estimated for the entire US population (Cleveland et al. 2000), and is well below the recommended 
Table 2. Means and percentages* of demographics, behaviours, diet, blood lipids and blood pressure by category of whole grain intake in 5496 participants, MESA 2000-2002\|

\begin{tabular}{|c|c|c|c|c|c|c|c|}
\hline & \multicolumn{6}{|c|}{ Whole grain intake category } & \multirow[b]{2}{*}{$P$ trend } \\
\hline & 1 & 2 & 3 & 4 & 5 & SEM $^{*}$ & \\
\hline \multicolumn{8}{|l|}{ Whole-grain intake (servings/d) } \\
\hline Median & 0.02 & 0.15 & 0.39 & 0.72 & 1.39 & & \\
\hline Range & $0.00-0.07$ & $0.08-0.26$ & $0.27-0.52$ & $0.53-0.96$ & $0.97-6 \cdot 14$ & & \\
\hline$N$ & 1069 & 1137 & 1072 & 1121 & 1097 & & \\
\hline \multicolumn{8}{|l|}{ Demographics } \\
\hline Male (\%) & $55 \cdot 8$ & $48 \cdot 3$ & $44 \cdot 8$ & $44 \cdot 3$ & $43 \cdot 0$ & 0.015 & $<0.0001$ \\
\hline Race (row \%) & & & & & & & $<0.0001 \ddagger$ \\
\hline White & $12 \cdot 7$ & $20 \cdot 7$ & $19 \cdot 8$ & $23 \cdot 7$ & $23 \cdot 2$ & & \\
\hline Black & $16 \cdot 4$ & $19 \cdot 7$ & $19 \cdot 3$ & $23 \cdot 3$ & 21.4 & & \\
\hline Hispanic & $23 \cdot 3$ & $21 \cdot 8$ & $20 \cdot 7$ & $16 \cdot 8$ & $17 \cdot 4$ & & \\
\hline Chinese & $42 \cdot 3$ & 21.4 & $17 \cdot 0$ & $9 \cdot 3$ & $10 \cdot 0$ & & \\
\hline Mean age (years) & $59 \cdot 4$ & $60 \cdot 8$ & 61.5 & $62 \cdot 9$ & $65 \cdot 0$ & 0.308 & $<0.0001$ \\
\hline Education (row \%) & & & & & & & $<0.0001 \S$ \\
\hline$<$ High school & $29 \cdot 9$ & $19 \cdot 1$ & $19 \cdot 7$ & $16 \cdot 1$ & $15 \cdot 3$ & & \\
\hline High school & $20 \cdot 3$ & $20 \cdot 8$ & $19 \cdot 8$ & $19 \cdot 6$ & 19.5 & & \\
\hline Some college & $18 \cdot 2$ & $21 \cdot 0$ & $19 \cdot 4$ & $21 \cdot 2$ & $20 \cdot 3$ & & \\
\hline Bachelors & $16 \cdot 0$ & $20 \cdot 8$ & $19 \cdot 6$ & $22 \cdot 9$ & $20 \cdot 8$ & & \\
\hline Graduate or professional degree & $14 \cdot 7$ & 21.9 & $19 \cdot 0$ & $21 \cdot 2$ & $23 \cdot 0$ & & \\
\hline \multicolumn{8}{|l|}{ Behaviours } \\
\hline Smoked within past $30 \mathrm{~d}(\%)$ & $18 \cdot 1$ & 13.4 & $13 \cdot 6$ & 9.5 & $8 \cdot 3$ & 0.010 & $<0.0001$ \\
\hline Alcohol $(g / d)$ & $5 \cdot 2$ & $4 \cdot 6$ & 4.5 & 3.9 & 3.5 & 0.277 & $<0.0001$ \\
\hline HRT (women only) \% current use & $30 \cdot 4$ & 33.4 & 30.5 & 35.5 & 30.5 & 0.021 & 0.62 \\
\hline $\begin{array}{l}\text { Leisure physical activity } \\
\text { (MET min/week) }\end{array}$ & 2285 & 2510 & 2340 & 2703 & 2610 & $94 \cdot 244$ & 0.0004 \\
\hline $\begin{array}{l}\text { Sedentariness score (MET min/week) } \\
\text { Mean dietary intake }\end{array}$ & 1702 & 1755 & 1685 & 1655 & 1588 & $34 \cdot 004$ & 0.003 \\
\hline Energy $(\mathrm{kJ} / \mathrm{d})$ & 6250 & 6672 & 7027 & 7228 & 8135 & $22 \cdot 741$ & $<0.0001$ \\
\hline Refined grain (servings/d) & 2.03 & 1.95 & 1.92 & 1.83 & 1.64 & 0.026 & $<0.0001$ \\
\hline Fruit (servings/d) & 1.89 & 2.00 & 2.09 & 2.44 & 2.69 & 0.049 & $<0.0001$ \\
\hline Vegetables (servings/d) & 2.46 & $2 \cdot 60$ & 2.65 & $2 \cdot 82$ & 2.79 & 0.042 & $<0.0001$ \\
\hline Dairy (servings/d) & 1.51 & 1.62 & 1.66 & 1.69 & 1.79 & 0.039 & 0.0002 \\
\hline Fish/poultry (servings/d) & 0.98 & 0.99 & 1.00 & 1.02 & 0.94 & 0.017 & 0.02 \\
\hline Meat (servings/d) & 0.65 & 0.61 & 0.57 & 0.52 & 0.41 & 0.012 & $<0.0001$ \\
\hline \multicolumn{8}{|l|}{ Blood lipids and blood pressure (BP) } \\
\hline HDL-cholesterol (mg/dl) & $51 \cdot 8$ & $51 \cdot 8$ & $51 \cdot 4$ & 51.5 & $51 \cdot 3$ & 0.429 & 0.45 \\
\hline LDL-cholesterol (mg/dl) & $118 \cdot 1$ & 117.5 & $119 \cdot 0$ & $118 \cdot 3$ & $117 \cdot 0$ & 0.974 & 0.23 \\
\hline Systolic BP $(\mathrm{mmHg})$ & $126 \cdot 3$ & $125 \cdot 6$ & 125.4 & 125.7 & $125 \cdot 0$ & 0.605 & 0.17 \\
\hline Diastolic BP (mmHg) & $72 \cdot 2$ & 71.7 & 72.0 & $72 \cdot 1$ & 71.6 & 0.302 & 0.21 \\
\hline
\end{tabular}

intake (US Department of Health \& Human Services \& the US Department of Agriculture, 2005) of three or more servings of whole grain foods per $\mathrm{d}$. In fact, less than $1 \%$ of participants met the official recommendation of three or more servings per d. About $20 \%$ of white, black and Hispanic participants reported eating one or more servings per $d$, but less than $10 \%$ of Chinese participants ate whole grain foods that often. As in previous papers (Jacobs et al. 1998; Steffen et al. 2003b), we found that whole grain food intake was a good indicator of other healthful behaviours, with higher consumption associated with being a non-smoker, drinking less alcohol, more leisure physical activity, less sedentary behaviour and greater consumption of fruit, vegetables and dairy and less of meat and refined grains.

These findings in the MESA database are consistent with several studies that have observed more favourable values of
BMI, insulin and diabetes among whole grain eaters (Lovejoy \& DiGirolamo, 1992; Feskens et al. 1994; Marshall et al. 1997; Ludwig et al. 1999; Liu et al. 2000, 2003; Meyer et al. 2000; Fung et al. 2002; Pereira et al. 2002; Liese et al. 2003; Montonen et al. 2003; Steffen et al. 2003a). Graded inverse relationships were observed between whole grain intake and BMI, serum insulin, homeostasis model assessment insulin resistance, glucose, and newly diagnosed impaired fasting glucose or diabetes.

As observed in other studies (Jensen et al. 2006; Lutsey et al. 2006), there was a strong inverse association between homocysteine and whole grain intake. This is as expected, since whole grains are a rich source of folate, which is inversely related to homocysteine (Wardlaw \& Kessel, 2002). Several food-based feeding trials have also shown reductions in homocysteine resulting from increased consumption of whole grains 
Table 3. Means and percentages of body mass index, insulin resistance, inflammation, diabetes and subclinical CVD by category of whole grain intake in 5496 participants, MESA 2000-2002§

\begin{tabular}{|c|c|c|c|c|c|c|c|c|}
\hline \multirow[b]{2}{*}{ CVD risk factor } & \multirow[b]{2}{*}{ Model } & \multicolumn{6}{|c|}{ Whole grain intake category } & \multirow[b]{2}{*}{$P$ trend } \\
\hline & & 1 & 2 & 3 & 4 & 5 & SEM $^{*}$ & \\
\hline Median whole grain intake & & 0.02 & 0.15 & 0.39 & 0.72 & $1 \cdot 39$ & & \\
\hline$n$ & & 1069 & 1137 & 1072 & 1121 & 1097 & & \\
\hline \multirow[t]{2}{*}{$\mathrm{BMI}\left(\mathrm{kg} / \mathrm{m}^{2}\right)$} & 1 & $28 \cdot 2$ & $28 \cdot 2$ & $28 \cdot 0$ & $27 \cdot 7$ & $27 \cdot 4$ & 0.153 & $<0.0001$ \\
\hline & 2 & $28 \cdot 2$ & $28 \cdot 2$ & $27 \cdot 9$ & $27 \cdot 8$ & $27 \cdot 6$ & $0 \cdot 151$ & $<0.0001$ \\
\hline \multirow[t]{2}{*}{ Insulint (mU/l) } & 1 & 5.44 & 5.48 & 5.45 & $5 \cdot 15$ & 4.96 & 0.019 & $<0.0001$ \\
\hline & 2 & $5 \cdot 37$ & 5.42 & 5.42 & $5 \cdot 19$ & $5 \cdot 16$ & 0.019 & 0.002 \\
\hline \multirow{2}{*}{ HOMA (mU//*mmol/l) } & 1 & 1.70 & 1.72 & 1.64 & 1.54 & 1.50 & 0.043 & $<0.0001$ \\
\hline & 2 & 1.68 & 1.70 & 1.63 & 1.55 & 1.53 & 0.043 & 0.002 \\
\hline \multirow[t]{3}{*}{ CRPt (mg/l) } & 1 & 3.56 & $3 \cdot 31$ & $3 \cdot 23$ & $3 \cdot 18$ & 3.02 & 0.022 & $<0.0001$ \\
\hline & 2 & 3.48 & $3 \cdot 26$ & $3 \cdot 20$ & $3 \cdot 22$ & $3 \cdot 12$ & 0.022 & 0.004 \\
\hline & 3 & 3.43 & 3.22 & $3 \cdot 20$ & $3 \cdot 24$ & $3 \cdot 17$ & 0.021 & 0.08 \\
\hline \multirow[t]{3}{*}{ IL-6 (pg/ml) } & 1 & 1.59 & 1.50 & 1.46 & 1.48 & 1.45 & 0.037 & 0.03 \\
\hline & 2 & 1.56 & 1.49 & 1.45 & 1.50 & 1.48 & 0.037 & 0.39 \\
\hline & 3 & 1.54 & 1.47 & 1.45 & 1.51 & 1.51 & 0.035 & 0.92 \\
\hline \multirow[t]{3}{*}{ Homocysteine $(\mu \mathrm{mol} / \mathrm{l})$} & 1 & $9 \cdot 68$ & $9 \cdot 34$ & 9.35 & 9.01 & $8 \cdot 77$ & 0.113 & $<0.0001$ \\
\hline & 2 & $9 \cdot 62$ & 9.32 & $9 \cdot 34$ & 9.05 & 8.80 & 0.113 & $<0.0001$ \\
\hline & 3 & 9.62 & $9 \cdot 32$ & $9 \cdot 34$ & 9.05 & $8 \cdot 82$ & 0.113 & $<0.0001$ \\
\hline \multirow[t]{3}{*}{ Glucose (mg/dl) } & 1 & $99 \cdot 3$ & 99.0 & $97 \cdot 3$ & $98 \cdot 4$ & $96 \cdot 9$ & 0.580 & 0.001 \\
\hline & 2 & $99 \cdot 2$ & $98 \cdot 9$ & $97 \cdot 3$ & 98.4 & $97 \cdot 2$ & 0.580 & 0.008 \\
\hline & 3 & 99.0 & $98 \cdot 7$ & $97 \cdot 2$ & 98.5 & $97 \cdot 6$ & 0.580 & 0.08 \\
\hline \multirow[t]{3}{*}{ IFG or newly diagnosed diabetes (\%) } & 1 & 38.4 & 35.4 & $33 \cdot 2$ & $34 \cdot 1$ & $32 \cdot 1$ & 0.015 & 0.004 \\
\hline & 2 & $38 \cdot 2$ & $35 \cdot 1$ & 33.2 & 34.2 & 32.5 & 0.015 & 0.02 \\
\hline & 3 & $37 \cdot 7$ & 34.4 & $32 \cdot 7$ & 34.7 & $33 \cdot 8$ & 0.014 & 0.23 \\
\hline \multirow[t]{3}{*}{ Newly diagnosed diabetes (\%) } & 1 & $4 \cdot 0$ & $4 \cdot 7$ & 3.5 & 3.7 & $3 \cdot 6$ & 0.006 & 0.16 \\
\hline & 2 & 3.9 & 4.7 & 3.5 & $3 \cdot 7$ & $3 \cdot 8$ & 0.006 & 0.33 \\
\hline & 3 & $3 \cdot 8$ & 4.5 & $3 \cdot 4$ & $3 \cdot 7$ & $4 \cdot 1$ & 0.006 & 0.63 \\
\hline \multirow[t]{3}{*}{ Urine albumin excretiont $(\mathrm{mg} / \mathrm{g})$} & 1 & $7 \cdot 30$ & 7.59 & $6 \cdot 71$ & $7 \cdot 00$ & $6 \cdot 72$ & 0.006 & 0.03 \\
\hline & 2 & $7 \cdot 22$ & 7.55 & $6 \cdot 69$ & 7.04 & $6 \cdot 82$ & 0.018 & 0.20 \\
\hline & 3 & $7 \cdot 19$ & 7.51 & $6 \cdot 66$ & 7.07 & $6 \cdot 88$ & 0.023 & 0.38 \\
\hline \multirow[t]{3}{*}{$\% \mathrm{~A} / \mathrm{kC}>25$} & 1 & $10 \cdot 7$ & $12 \cdot 5$ & $9 \cdot 2$ & $10 \cdot 2$ & 8.9 & 0.009 & 0.05 \\
\hline & 2 & $10 \cdot 4$ & $12 \cdot 3$ & $9 \cdot 1$ & $10 \cdot 4$ & 9.4 & 0.009 & 0.28 \\
\hline & 3 & $10 \cdot 3$ & $12 \cdot 2$ & $9 \cdot 0$ & $10 \cdot 6$ & 9.5 & 0.009 & 0.39 \\
\hline \multirow[t]{3}{*}{ Common carotid IMT† (mm) } & 1 & 0.853 & 0.857 & 0.850 & 0.849 & 0.850 & 0.002 & 0.26 \\
\hline & 2 & 0.852 & 0.856 & 0.850 & 0.850 & 0.852 & 0.003 & 0.48 \\
\hline & 3 & 0.851 & 0.855 & 0.849 & 0.851 & 0.854 & 0.003 & 0.98 \\
\hline \multirow[t]{3}{*}{ Internal carotid IMT† (mm) } & 1 & 0.986 & 0.994 & 0.981 & 0.966 & 0.985 & 0.007 & 0.49 \\
\hline & 2 & 0.977 & 0.990 & 0.978 & 0.971 & 0.996 & 0.011 & 0.59 \\
\hline & 3 & 0.975 & 0.988 & 0.977 & 0.972 & 0.999 & 0.012 & 0.42 \\
\hline \multirow[t]{3}{*}{$\%$ with plaque } & 1 & $42 \cdot 2$ & $40 \cdot 9$ & $39 \cdot 2$ & $36 \cdot 9$ & 39.4 & 0.014 & 0.21 \\
\hline & 2 & $41 \cdot 1$ & 40.5 & 38.9 & 37.5 & 40.5 & 0.014 & 0.97 \\
\hline & 3 & $41 \cdot 1$ & $40 \cdot 3$ & $38 \cdot 8$ & $37 \cdot 6$ & $40 \cdot 6$ & 0.014 & 0.84 \\
\hline \multirow[t]{3}{*}{ Agatston score†‡ } & 1 & 7.037 & $7 \cdot 130$ & 7.510 & 7.993 & 6.553 & 0.025 & 0.10 \\
\hline & 2 & 6.788 & $7 \cdot 018$ & 7.486 & $8 \cdot 106$ & $6 \cdot 825$ & 0.046 & 0.34 \\
\hline & 3 & $6 \cdot 711$ & 6.918 & 7.445 & $8 \cdot 185$ & 6.975 & 0.057 & 0.58 \\
\hline \multirow[t]{3}{*}{$\%$ Agatston score $>0$} & 1 & 48.9 & $48 \cdot 6$ & $48 \cdot 6$ & $49 \cdot 8$ & $46 \cdot 6$ & 0.014 & 0.05 \\
\hline & 2 & 48.4 & $48 \cdot 4$ & $48 \cdot 6$ & $50 \cdot 0$ & $47 \cdot 2$ & 0.014 & 0.15 \\
\hline & 3 & $48 \cdot 2$ & $48 \cdot 2$ & 48.5 & $50 \cdot 2$ & $47 \cdot 6$ & 0.014 & 0.33 \\
\hline
\end{tabular}

Model 1 (base model), age, sex, race, education, survey centre and energy intake.

Model 2 (behavioural model), model 1 plus current smoking, current alcohol use and dietary intake of fruit, vegetables, refined grains, dairy, fish and poultry, meat, leisure physical activity, and sedentariness score.

Model 3 (mechanistic model), model 2 plus BMI and insulin.

${ }^{*}$ Calculated as root MSE/(mean $n$ per quintile) is included to facilitate statistical comparison of pairs of whole grain quintiles.

† Geometric mean.

$\ddagger$ Zero values were included.

$\S$ For details of subjects and procedures, see Methods.

MESA, Multi-Ethnic Study of Atherosclerosis; HOMA, homeostasis model assessment; CRP, C-reactive protein; IFG, impaired fasting glucose; A/kC, sex-standardized albumin: creatinine ratio where $\mathrm{k}=1$ for women and 0.68 for men; IMT, intima-media thickness.

(Jang et al. 2001), fortified cereals (Malinow et al. 1998; Riddell et al. 2000) and cereals prior to folic acid fortification of refined grain food starting in 1998 (Tucker et al. 2000).

In recent literature, inverse associations were observed between whole grain intake and inflammatory markers in a subset of men from the Health Professionals Follow-Up Study and women from the Nurses' Health Study II (Jensen et al. 2006); however, all became non-significant after accounting for lifestyle factors. In our analysis, CRP remained inversely associated with whole grain intake after adjustment for other behavioural characteristics, although the relationship was partially explained by adjustment for BMI and insulin, two factors that are believed to be in the causal pathway. IL-6 was inversely associated with whole grain intake after 
minimal adjustment; however, significance was not retained with further adjustment. No association between whole grain intake and IL-6 was observed in a previous study (Jensen et al. 2006). Another recent study among female nurses with type 2 diabetes observed inverse associations (Qi et al. 2006) of whole grain intake and both CRP and TNF receptor 2. Dietary fibre has also been inversely associated with serum CRP concentrations (King et al. 2003; Ajani et al. 2004).

As hypothesized, urine albumin excretion and microalbuminuria prevalence had inverse associations with whole grain intake in the base model. However, these associations became non-significant after additional adjustments. Urine albumin excretion was the only variable studied in which the present data suggested a race/ethnicity interaction; even in the fully adjusted models, Chinese and Hispanic participants showed an inverse association between whole grain intake and urine albumin excretion rate, whereas whites and blacks showed no relationship even in the base model. However, given the large number of variables assessed, this heterogeneity by ethnic group may have been a chance finding. To our knowledge no previous studies have examined the relationship between whole grain intake and urine albumin excretion or microalbuminuria. Total dietary fibre has, however, been evaluated, with one study showing reduced albuminuria among those consuming $>26 \mathrm{~g} / \mathrm{d}$ (Metcalf et al. 1993) and the other showing no effect (Watts et al. 1988).

In contrast and contrary to our initial hypotheses, however, whole grain intake showed little cross-sectional relationship with subclinical markers of vascular disease. There was limited evidence that whole grain intake was inversely associated with $\mathrm{CAC}$, but no evidence that whole grain intake was predictive of carotid artery intima-media thickness. Associations of whole grain intake with these markers have not previously been reported. Numerous prospective studies have found graded and continuous relationships between subclinical disease and CVD outcomes (Levy et al. 1989; Chambless et al. 1997; O'Leary et al. 1999; Raggi et al. 2000), yet they occur early in the atherosclerotic process and do not reflect impending clinical disease. The subclinical disease markers used here are relatively weakly correlated and therefore heterogeneous. Thus, another possible explanation is that although whole grain may have an influence on atherosclerosis, measurement of CAC and intima-media thickness may be too loosely connected to the whole body burden of atherosclerosis to detect this influence. Furthermore, it is possible that whole grain intake reduces risk of $\mathrm{CHD}$ in ways other than through direct reduction of atherosclerosis. The failure to find associations between whole grain intake and these subclinical markers may reflect the cross-sectional design. A cause-effect relationship cannot be inferred from these data and reverse causality may be an issue. For example, despite participants being free of clinical CVD at baseline, it is possible that participants at greater risk for CVD may have begun taking behavioural precautions to reduce their risk of having a CVD event, such as increasing their whole grain intake. Given the lack of follow-up, whether whole grain intake is associated with progression of subclinical disease or incidence of clinical events was not studied. Ongoing MESA follow-up will help to overcome this limitation.

Another limitation of the study is that the dietary measure may have limited accuracy as it was based on a single FFQ.
Further, whole grain consumption was low and there was little variation. It is possible that there could be a threshold effect in which the impact of whole grains on subclinical markers is only evident at higher levels of consumption than reported in this study. Error in the measurement of potential confounders or failure to measure and adjust for potential confounders could have resulted in residual confounding. Ruling out the possibility of residual confounding is particularly difficult in this analysis, as whole grain consumers tend to report healthier lifestyle habits than non-consumers (Jacobs et al. 1998; Steffen et al. 2003b).

Strengths of this study are that MESA collected an extensive set of subclinical CVD measures in a large sample of participants using standardized procedures to increase measurement validity and that whole grain intake (including specific cereal brand) was reported by participants using a FFQ, which accounted for both frequency of consumption and serving size. Additionally, in light of recent discussions concerning both the benefits of whole food approaches (Jacobs \& Steffen, 2003) and possible limitations of single nutrient approaches in assessing relationships between diet and complex disease (Lichtenstein \& Russell, 2005), the fact that we assessed diet in terms of whole grain intake may be considered a strength of the present study.

In summary, in this multi-ethnic sample of 5496 men and women, we found ethnic differences in whole grain intake, but few ethnic differences in the associations of whole grain foods with several dependent variables. There were strong cross-sectional associations between whole grain consumption and healthful behaviour, BMI, insulin, homocysteine, CRP and fasting glucose and possible associations with measures of urine albumin excretion rate, but no associations with measures of carotid artery intima-medial thickness or CAC.

\section{Acknowledgements}

This research was supported by contracts N01-HC-95 159 through N01-HC-95 165 and N01-HC-95 169 from the National Heart, Lung, and Blood Institute. The authors thank the other investigators, the staff, and the participants of the MESA study for their valuable contributions. A full list of participating MESA investigators and institutions can be found at http://www.mesa-nhlbi.org

\section{References}

Ainsworth BE, Haskell WL, Whitt MC, et al. (2000) Compendium of physical activities: an update of activity codes and MET intensities. Med Sci Sports Exerc 32, S498-S504.

Ajani UA, Ford ES \& Mokdad AH (2004) Dietary fiber and C-reactive protein: findings from National Health And Nutrition Examination Survey data. J Nutr 134, 1181-1185.

Bild DE, Bluemke DA, Burke GL, et al. (2002) Multi-ethnic study of atherosclerosis: objectives and design. Am J Epidemiol 156, 871-881.

Block G, Woods M, Potosky A \& Clifford C (1990) Validation of a self-administered diet history questionnaire using multiple diet records. J Clin Epidemiol 43, 1327-1335.

Carr JJ, Crouse JR 3rd, Goff DC Jr, D'Agostino RB Jr, Peterson NP \& Burke GL (2000) Evaluation of subsecond gated helical CT for quantification of coronary artery calcium and comparison with electron beam CT. AJR Am J Roentgenol 174, 915-921. 
Carr JJ, Nelson JC, Wong ND, et al. (2005) Calcified coronary artery plaque measurement with cardiac CT in population-based studies: standardized protocol of Multi-Ethnic Study of Atherosclerosis (MESA) and Coronary Artery Risk Development in Young Adults (CARDIA) study. Radiology 234, 35-43.

Chambless LE, Heiss G, Folsom AR, et al. (1997) Association of coronary heart disease incidence with carotid arterial wall thickness and major risk factors: the Atherosclerosis Risk in Communities (ARIC) Study, 1987-1993. Am J Epidemiol 146, 483-494.

Cleveland LE, Moshfegh AJ, Albertson AM \& Goldman JD (2000) Dietary intake of whole grains. J Am Coll Nutr 19, Suppl. 3, 331S-338S.

Espeland MA, Evans GW, Wagenknecht LE, et al. (2003) Sitespecific progression of carotid artery intimal-medial thickness. Atherosclerosis 171, 137-143.

Feskens EJ, Loeber JG \& Kromhout D (1994) Diet and physical activity as determinants of hyperinsulinemia: the Zutphen Elderly Study. Am J Epidemiol 140, 350-360.

Fraser GE, Sabate J, Beeson WL \& Strahan TM (1992) A possible protective effect of nut consumption on risk of coronary heart disease. The Adventist Health Study. Arch Intern Med 152, $1416-1424$.

Fung TT, Hu FB, Pereira MA, et al. (2002) Whole-grain intake and the risk of type 2 diabetes: a prospective study in men. Am J Clin Nutr 76, 535-540.

Jacobs DR Jr \& Gallaher DD (2004) Whole grain intake and cardiovascular disease: a review. Curr Atheroscler Rep 6, 415-423.

Jacobs DR Jr, Meyer KA, Kushi LH \& Folsom AR (1998) Wholegrain intake may reduce the risk of ischemic heart disease death in postmenopausal women: the Iowa Women's Health Study. Am $J$ Clin Nutr 68, 248-257.

Jacobs DR Jr, Meyer KA, Kushi LH \& Folsom AR (1999) Is whole grain intake associated with reduced total and cause-specific death rates in older women? The Iowa Women's Health Study. Am J Public Health 89, 322-329.

Jacobs DR Jr, Meyer HE \& Solvoll K (2001) Reduced mortality among whole grain bread eaters in men and women in the Norwegian County Study. Eur J Clin Nutr 55, 137-143.

Jacobs DR Jr, Murtaugh MA, Steffes M, Yu X, Roseman J \& Goetz FC (2002) Gender- and race-specific determination of albumin excretion rate using albumin-to-creatinine ratio in single, untimed urine specimens: the Coronary Artery Risk Development in Young Adults Study. Am J Epidemiol 155, 1114-1119.

Jacobs DR Jr \& Steffen LM (2003) Nutrients, foods, and dietary patterns as exposures in research: a framework for food synergy. Am J Clin Nutr 78, Suppl. 3, 508S-513S.

Jang Y, Lee JH, Kim OY, Park HY \& Lee SY (2001) Consumption of whole grain and legume powder reduces insulin demand, lipid peroxidation, and plasma homocysteine concentrations in patients with coronary artery disease: randomized controlled clinical trial. Arterioscler Thromb Vasc Biol 21, 2065-2071.

Jensen MK, Koh-Banerjee P, Franz M, Sampson L, Gronbaek M \& Rimm EB (2006) Whole grains, bran, and germ in relation to homocysteine and markers of glycemic control, lipids, and inflammation 1. Am J Clin Nutr 83, 275-283.

King DE, Egan BM \& Geesey ME (2003) Relation of dietary fat and fiber to elevation of C-reactive protein. Am J Cardiol 92, $1335-1339$.

Levy D, Garrison RJ, Savage DD, Kannel WB \& Castelli WP (1989) Left ventricular mass and incidence of coronary heart disease in an elderly cohort. The Framingham Heart Study. Ann Intern Med 110, $101-107$.

Lichtenstein AH \& Russell RM (2005) Essential nutrients: food or supplements? Where should the emphasis be? JAMA 294, $351-358$.

Liese AD, Roach AK, Sparks KC, Marquart L, D'Agostino RB \& Mayer-Davis EJ (2003) Whole-grain intake and insulin sensitivity: the Insulin Resistance Atherosclerosis Study. Am J Clin Nutr 78, 965-971.

Liu S, Manson JE, Stampfer MJ, et al. (2000) A prospective study of whole-grain intake and risk of type 2 diabetes mellitus in US women. Am J Public Health 90, 1409-1415.

Liu S, Stampfer MJ, Hu FB, et al. (1999) Whole-grain consumption and risk of coronary heart disease: results from the Nurses' Health Study. Am J Clin Nutr 70, 412-419.

Liu S, Willett WC, Manson JE, Hu FB, Rosner B \& Colditz G (2003) Relation between changes in intakes of dietary fiber and grain products and changes in weight and development of obesity among middle-aged women. Am J Clin Nutr 78, 920-927.

Lovejoy J \& DiGirolamo M (1992) Habitual dietary intake and insulin sensitivity in lean and obese adults. Am J Clin Nutr 55, 1174-1179.

Ludwig DS, Pereira MA, Kroenke CH, et al. (1999) Dietary fiber, weight gain, and cardiovascular disease risk factors in young adults. JAMA 282, 1539-1546.

Lutsey PL, Steffen LM, Feldman HA, et al. (2006) Serum homocysteine is related to food intake in adolescents: The Child and Adolescent Trial for Cardiovascular Health (CATCH). Am J Clin Nutr 83, 1380-1386.

Malinow MR, Duell PB, Hess DL, et al. (1998) Reduction of plasma homocyst(e)ine levels by breakfast cereal fortified with folic acid in patients with coronary heart disease. $N$ Engl J Med 338, 1009-1015.

Marshall JA, Bessesen DH \& Hamman RF (1997) High saturated fat and low starch and fibre are associated with hyperinsulinaemia in a non-diabetic population: the San Luis Valley Diabetes Study. Diabetologia 40, 430-438.

Matthews DR, Hosker JP, Rudenski AS, Naylor BA, Treacher DF \& Turner RC (1985) Homeostasis model assessment: insulin resistance and beta-cell function from fasting plasma glucose and insulin concentrations in man. Diabetologia 28, 412-419.

Mayer-Davis EJ, Vitolins MZ, Carmichael SL, et al. (1999) Validity and reproducibility of a food frequency interview in a Multi-Cultural Epidemiology Study. Ann Epidemiol 9, 314-324.

Metcalf PA, Baker JR, Scragg RK, Dryson E, Scott AJ \& Wild CJ (1993) Dietary nutrient intakes and slight albuminuria in people at least 40 years old. Clin Chem 39, 2191-2198.

Meyer KA, Kushi LH, Jacobs DR Jr, Slavin J, Sellers TA \& Folsom AR (2000) Carbohydrates, dietary fiber, and incident type 2 diabetes in older women. Am J Clin Nutr 71, 921-930.

Montonen J, Knekt P, Jarvinen R, Aromaa A \& Reunanen A (2003) Whole-grain and fiber intake and the incidence of type 2 diabetes. Am J Clin Nutr 77, 622-629.

Morris JN, Marr JW \& Clayton DG (1977) Diet and heart: a postscript. Br Med J 2(6098), 1307-1314.

O’Leary DH, Polak JF, Kronmal RA, Manolio TA, Burke GL \& Wolfson SK Jr (1999) Carotid-artery intima and media thickness as a risk factor for myocardial infarction and stroke in older adults. Cardiovascular Health Study Collaborative Research Group. N Engl J Med 340, 14-22.

Pereira MA, Jacobs DR Jr, Pins JJ, et al. (2002) Effect of whole grains on insulin sensitivity in overweight hyperinsulinemic adults. Am J Clin Nutr 75, 848-855.

Pietinen P, Rimm EB, Korhonen P, et al. (1996) Intake of dietary fiber and risk of coronary heart disease in a cohort of Finnish men. The Alpha-Tocopherol, Beta-Carotene Cancer Prevention Study. Circulation 94, 2720-2727.

Qi L, van Dam RM, Liu S, Franz M, Mantzoros C \& Hu FB (2006) Whole-grain, bran, and cereal fiber intakes and markers of systemic inflammation in diabetic women. Diabetes Care 29, 207-211.

Raggi P, Callister TQ, Cooil B, et al. (2000) Identification of patients at increased risk of first unheralded acute myocardial infarction by electron-beam computed tomography. Circulation 101, 850-855. 
Riddell LJ, Chisholm A, Williams S \& Mann JI (2000) Dietary strategies for lowering homocysteine concentrations. Am J Clin Nutr 71, $1448-1454$.

Steffen LM, Jacobs DR Jr, Murtaugh MA, et al. (2003a) Whole grain intake is associated with lower body mass and greater insulin sensitivity among adolescents. Am J Epidemiol 158, 243-250.

Steffen LM, Jacobs DR Jr, Stevens J, Shahar E, Carithers T \& Folsom AR (2003b) Associations of whole-grain, refined-grain, and fruit and vegetable consumption with risks of all-cause mortality and incident coronary artery disease and ischemic stroke: the Atherosclerosis Risk in Communities (ARIC) Study. Am J Clin Nutr 78, 383-390.

Tucker KL, Bermudez OI \& Castaneda C (2000) Type 2 diabetes is prevalent and poorly controlled among Hispanic elders of Caribbean origin. Am J Public Health 90, 1288-1293.
US Department of Health and Human Services \& the US Department of Agriculture (2005) Dietary Guildelines for Americans 2005 (www.healthierus.gov/dietaryguidelines ed).

Vitelli LL, Folsom AR, Shahar E, et al. (1996) Association of dietary composition with fasting serum insulin level: the ARIC Study. Nutr Metab Cardiovasc Dis 6, 194-202.

Wardlaw GM \& Kessel M (2002) Perspectives in Nutrition, 5th ed. Boston, MA: McGraw-Hill.

Warram JH, Gearin G, Laffel L \& Krolewski AS (1996) Effect of duration of type I diabetes on the prevalence of stages of diabetic nephropathy defined by urinary albumin/creatinine ratio. $J$ Am Soc Nephrol 7, 930-937.

Watts GF, Gregory L, Naoumova R, Kubal C \& Shaw KM (1988) Nutrient intake in insulin-dependent diabetic patients with incipient nephropathy. Eur J Clin Nutr 42, 697-702. 